\title{
Busca de superação das contradições da forma escolar no movimento de formação contínua de professores que ensinam matemática
}

\author{
Search for overcoming the school form's contradictions in the \\ continuing education movement of teachers that teach mathematics
}

\section{Neusa Maria Marques de Souza ${ }^{1}$ Anelisa Kisielewski Esteves ${ }^{2}$}

\begin{abstract}
RESUMO
A natureza deste artigo vincula-se à formação contínua de professores que ensinam Matemática e à necessidade de movimentos formativos que propiciem o enfrentamento das contradições postas pela forma escolar, assim como à busca de sua superação. Subsidiam as argumentações alguns dados de uma pesquisa de doutorado que teve como objetivo investigar, no processo formativo, a relação conteúdo e forma na atividade de ensino de Matemática de professores do ensino fundamental. Os aportes teórico-metodológicos basearam-se nos fundamentos da teoria históricocultural, com enfoque na teoria da atividade e no método em Vigotski. Das evidências, destacamos que a convergência entre atividade de formação e de ensino do professor propiciadas pelo processo formativo na e com a escola operaram vias de aproximação dos motivos dos sujeitos com os do conteúdo da formação e caminhos constantes para o enfrentamento das contradições da forma escolar, cuja superação torna-se condição para que mudanças ocorram no conteúdo e forma da atividade de ensino.
\end{abstract}

\begin{abstract}
The nature of this paper is related to the teachers' continuous formation teach mathematics, and the need for formative movements, which allow the confrontation of the contradictions posed, by the school form, and the search for its overcoming. It subsidies the arguments, some data from a doctorate research that had the objective of investigating, in the formative process, the content and form relation in the teaching activity of mathematics from the elementary school teachers. The theoretic-methodological contributions were based on the foundations of the historical-cultural theory, focusing on the theory of activity and the method in Vigotski. From the evidences, we emphasize that the convergence between training activity and teacher education provided by the formative process in and with the school, operated ways of approaching the subjects' motives with those of the content of the formation and constant paths to the confrontation of the contradictions of the school form, whose overcoming becomes a condition for changes to occur in the content and form of the teaching activity.
\end{abstract}

\footnotetext{
1 Possui Pós-doutorado na FE/USP/SP em Educação Matemática (2013); Doutorado em Educação (Currículo) (2003) na PUC/SP; Mestrado em Educação (1994) na UNESP/Marília-SP; Graduação em Matemática (1984) e em Pedagogia (1988); Atualmente é Professora Visitante no Programa de Pós-Graduação Educação em Ciências e Matemática (Mestrado e Doutorado) na Universidade Federal de Goiás-Goiânia-GO e Docente colaboradora do programa de Pós Graduação em Educação Matemática (Mestrado e Doutorado) na Universidade Federal de Mato Grosso do Sul. E-mail: neusamms@uol.com.br

2 Possui Doutorado em Educação (2016) e Mestrado em Educação Matemática (2009) pela Universidade Federal de Mato Grosso do Sul; Graduação em Pedagogia pela UNAES/Campo Grande-MS. Atualmente é Professora da Rede Municipal de Educação de Campo Grande-MS e Docente da Universidade AnhangueraUniderp de Campo Grande-MS. E-mail: anelisake@gmail.com
} 
Palavras-chave: Teoria Histórico-Cultural. Formação Contínua de Professores. Contradição/Superação/Conteúdo-Forma.
Keywords: Historical-Cultural Theory. Continuing Teacher Training. Contradiction / Overcoming / Content-form.

\section{Introdução}

As condições desfavoráveis de trabalho do professor na atual forma escolar ${ }^{3}$ interferem e dificultam o desenvolvimento de ações que possam contribuir com possíveis mudanças no conteúdo e na forma da sua atividade de ensino, à medida que o tempo reservado a estudos, reflexões sobre as suas ações, compartilhamento de experiências e resolução de problemas que o professor enfrenta em sua prática pedagógica é suplantado pelo incentivo à repetição e automatização de um trabalho docente solitário e individualizado.

A sua rotina de trabalho é caracterizada por ações sequenciais, modeladas por diretrizes definidas pelos órgãos centralizadores da gestão educacional. Ademais, desenvolve-se na complexa rede de relações em que a forma escolar se estabelece e configura-se como via única a seguir, para dar cumprimento às metas estabelecidas para o trabalho do professor.

Neste quadro em que se produz a alienação do trabalho docente, reduzemse as possibilidades dos momentos coletivos em que se possa questionar a necessidade da avalanche de tarefas de toda ordem a serem cumpridas pelo professor, como escrituração e preenchimento de uma infinidade de formulários e outros trabalhos que, em tempos idos, eram destinados a funcionários de secretarias escolares, ou mesmo de pensarem-se novos modos de organizar o ensino para além dos modelos pré-estabelecidos.

\footnotetext{
${ }^{3}$ A forma escolar, à qual nos referimos, é compreendida a partir de estudos de Canário (2005, p.40), como "forma de conceber o processo de ensino/aprendizagem, a partir da criação de uma relação social, [...] a relação "pedagógica" entre um professor e um grupo homogéneo de alunos. Essa relação tende, por um lado, a autonomizar-se das restantes relações sociais e, por outro lado, a tornar-se hegemónica, relativamente a outras modalidades de pensar e organizar as aprendizagens.”.
} 
Estudos, tais como os que Gatti e Barreto (2009), Nacarato, Mengali e Passos (2009), Esteves (2009) e Martins (2010) fizeram sobre programas de formação continuada de professores instituídos nos últimos tempos, apontam que essas formações de modo geral, tanto nos programas desenvolvidos pelo governo federal como nas propostas de formação organizadas pelas próprias secretarias de educação, pouco têm contribuído para mudanças significativas nos processos de ensino e de aprendizagem.

Um breve olhar sobre tais programas de formação é capaz de revelar que, salvo em raras exceções, suas ações desenvolvem-se em espaços e tempos externos ao contexto e aos problemas vividos pelos professores em sua atuação e reproduzem-se nos moldes da escola tradicionalmente pensada como local de transmissão de conhecimentos.

Assim, teoria e prática acabam sendo tratadas como entidades paralelas pela cisão que se opera entre as necessidades próprias do trabalho docente e o conteúdo da formação. Como decorrência, após o período específico das ações de formação, os sujeitos tendem a retornar às práticas escolares nos mesmos moldes anteriormente praticados, sem que qualquer mudança da qualidade do ensino decorrente do trabalho formativo possa vir a operar-se.

Se entendermos que todo processo individual possui raízes sócio históricas, tendo, no coletivo, o referencial de seu desenvolvimento, nos deparamos com a impossibilidade de pensarmos os processos de formação de professores descolados dos condicionantes impostos pela realidade objetiva na qual realizam o seu trabalho.

Segundo tal entendimento e na busca pela compreensão sobre como organizar os processos de formação contínua de modo que eles possibilitem mudanças no conteúdo e forma ${ }^{4}$ da atividade de ensino do professor, tomaremos como base, para nossas discussões, algumas evidências obtidas nos dados de uma pesquisa desenvolvida pelas autoras em um programa de doutorado.

A utilização do termo educação contínua de professores, ao invés de continuada, como aparece nos documentos oficiais, vincula-se aos pressupostos da

\footnotetext{
${ }^{4}$ Conteúdo e forma são referidos, neste artigo, como categorias dialéticas que serão conceituadas ao longo do texto.
} 
Teoria Histórico-Cultural, a partir dos quais compreendemos o professor como sujeito social em ininterrupta formação e, ainda, que a atividade de formação se dá no movimento em que o professor se apropria tanto de conhecimentos relativos ao conteúdo a ser ensinado, como das formas de organização do ensino através do qual forma os seus alunos.

O trabalho de campo da pesquisa anteriormente mencionada desenvolveuse nos anos de 2013 e 2014 por meio de um movimento formativo, em uma escola municipal em tempo integral, em Campo Grande/MS, junto a um grupo de professores e coordenadores pedagógicos de $1^{\circ}$ ao $5^{\circ}$ ano do Ensino Fundamental.

Tal movimento formativo foi estruturado por ações formativas que se desenvolveram no interior da escola, por um processo permeado por ações de estudos com professores que ensinam Matemática, momentos de discussão a respeito de questões relacionadas aos conhecimentos matemáticos em si, análise das práticas pedagógicas dos participantes, planejamento coletivo das atividades de ensino a serem desenvolvidas e também pelos momentos de socialização das suas experiências e ações de ensino.

Os pressupostos teórico-metodológicos da teoria histórico-cultural, com enfoque na teoria da atividade e no método em Vigotski, fundamentaram as ações formativas desenvolvidas e a sua posterior análise.

\section{Aportes teóricos e metodológicos}

O debate acerca da formação docente envolve a centralidade da educação escolar no processo de desenvolvimento humano, via pela qual os processos mediados e intencionais propiciam aos sujeitos a possibilidade de apropriarem-se da "cultura material e espiritual", encarnada nos produtos da produção humana, nas relações que estabelecem "com os fenômenos do mundo circundante através de outros homens". (LEONTIEV, 2004, p. 290). A teoria da atividade traz, com base nos princípios da teoria histórico-cultural, contribuições importantes para pensarmos o papel da educação no desenvolvimento humano, com especial atenção à educação escolar e à formação de professores. 
Neste sentido, compreendemos que os processos formativos devem possibilitar ao professor, em atividade de formação, a apropriação tanto de conhecimentos relativos ao conteúdo a ser ensinado como sobre as formas de organização do ensino. Tais processos devem, portanto, subsidiar o acesso dos professores aos saberes do espaço educacional e propiciar o envolvimento na busca constante de conhecimentos balizadores da organização do ensino e da concretização de um projeto educativo proposto pelo coletivo escolar. (MOURA, 1996).

A atividade de ensino é a essência do trabalho docente, o que demanda modos de organizar esse ensino para o desempenho de sua função. As ações do professor dependem de tal organização para que se estabeleça, de forma sistemática e intencional, a aprendizagem do aluno. (MOURA; MORETTI, 2010). Entretanto, para discutirmos a atividade do professor, é preciso considerar a função da educação escolar na perspectiva teórica adotada por nós.

Sob a ótica da psicologia histórico-cultural, para que o homem possa desenvolver-se, é necessário que se aproprie, por meio de uma atividade mediatizada, da experiência social cristalizada nos objetos e fenômenos culturais e esta não lhe é dada imediatamente apenas pelo contato com esses objetos e fenômenos. Muitos são os conhecimentos produzidos historicamente pela humanidade, logo é necessário que sejam socializados de forma organizada e intencional, por meio de instituições educativas.

Os processos de formação contínua precisam, realmente, configurarem-se como uma atividade para o professor, conforme nos conceitua Leontiev (1983, 2004), nascida de uma necessidade orientada para um objeto, que gera um motivo que impulsiona o sujeito a agir, o que ocorre por meio de ações e operações que visam a atingir um determinado objetivo.

Além de processos de formação que realmente configurem-se como atividade para o professor superar as contradições que envolvem o seu fazer pedagógico, esses processos são um grande desafio para que se operem mudanças. As relações dialéticas entre conteúdo e forma - como também acontece com outras categorias da filosofia marxista - são fonte de desenvolvimento e, 
consequentemente, de mudanças qualitativas para a educação escolar, pois "a luta de contrários culmina na passagem de um estado qualitativo a outro." (ROSENTAL, STRAKS, 1960, p. 39) ${ }^{5}$

Os processos de mudança nos sujeitos estão diretamente vinculados às transformações que ocorrem no nível da consciência e essas alterações, por sua vez, dependem de processos socialmente mediados que estabeleçam conexões com o nível superior de pensamento. Entretanto, ações que levam o pensamento dos sujeitos a estabelecer conexões simples, no âmbito do pensamento empírico, porquanto mediadas pelos conceitos espontâneos, não operam transformações da consciência.

Sobre os conceitos espontâneos ou cotidianos e os científicos ou não cotidianos, Vigotski (1983) defende que os conceitos espontâneos são formados no cotidiano, por meio da experiência concreta, na comunicação direta com as pessoas. Já os conceitos científicos formam-se por meio da educação escolar, segundo um processo orientado, organizado e sistemático, envolvendo a realização de ações mentais de abstração e generalização.

Portanto, conforme os pressupostos da psicologia histórico-cultural e da pedagogia histórico-crítica, é papel da educação escolar propiciar aos alunos, de forma intencional e sistematizada, a apropriação do conhecimento científico de modo a promover o desenvolvimento máximo das capacidades humanas. Davídov (1998, p. 3), em seus estudos acerca da relação entre educação escolar e desenvolvimento, afirma sobre o papel da escola:

[...] a tarefa da escola contemporânea não consiste em dar às crianças uma grande quantidade de informações, mas sim em ensinar-lhes a orientar-se independentemente na informação científica e em qualquer outra. Isto significa que a escola deve ensinar aos alunos a pensar, a decidir, isto é, desenvolver ativamente os fundamentos do pensamento contemporâneo, para o qual é necessário organizar um ensino que impulsione o desenvolvimento (Vamos chamá-lo desenvolvimenta). (Grifos do autor).

\footnotetext{
5 As autoras optaram por apresentar, no corpo do texto, por tradução livre, em língua portuguesa, as citações de obras referenciadas em outra língua.
} 
Reforça-se, aqui, um dos pressupostos dos estudos de Vigotski (2010): o ensino deve promover o desenvolvimento. Contudo, não é qualquer ensino que garante desenvolvimento. A apropriação de conceitos científicos vai muito além da aquisição de novas informações, trata-se, na verdade, da possibilidade de formação de um sistema de pensamento organizado, que dirige o pensamento para a própria atividade mental (SFORNI, 2004).

Considerando as diferenças entre os processos de formação dos conceitos espontâneos e dos conceitos científicos, Davídov (1982, 1988) analisa o desenvolvimento de dois tipos de pensamento: o empírico e o teórico. Segundo o autor, o pensamento empírico "[...] se constitui como uma forma transformada e expressa verbalmente da atividade dos órgãos dos sentidos, ligada com a vida real; é derivado diretamente da atividade objetal-sensorial das pessoas. " (DAVÍDOV, 1988, p. 123). O pensamento teórico, por sua vez, tem como conteúdo a existência mediatizada, refletida, essencial e consiste em "[...] um processo de idealização de um dos aspectos da atividade objetal-prática, a reprodução, que representa as formas universais dos objetos." (DAVÍDOV, 1988, p. 125).

O ensino baseado na lógica formal propicia apenas o desenvolvimento do pensamento empírico e, para que haja transformação dos sujeitos, "é necessário reorientar todo sistema escolar a formar nas crianças não o pensamento discursivo-empírico, mas desenvolver neles o pensamento científico-teórico contemporâneo." (DAVÍDOV, 1982, p. 442, grifos do autor).

Os caminhos em que se definem e organizam os processos formativos para que as relações anteriormente pontuadas possam consolidar-se, demandam a clareza que mudanças na atividade de ensino dependem da apropriação, por parte dos professores, de novas significações acerca do próprio objeto de ensino. Em outros termos, o conteúdo da atividade de ensino precisa ser modificado, pois, conforme estudos de Cheptulin (1982), Fischer (1976) e Rosental e Straks (1960), a mudança da forma está sujeita à mudança do conteúdo.

Pensar sobre a relação conteúdo/forma na atividade do professor implica, desse modo, considerar que é necessário provocar, primeiramente, mudanças no conteúdo da atividade de ensino, pois é apenas "em decorrência do acúmulo das 
mudanças quantitativas no conteúdo, [que] haverá, cedo ou tarde, uma mudança da forma, que é acompanhada pela passagem da formação material para um novo estado qualitativo." (CHEPTULIN, 1982, p. 348).

Portanto, na relação dialética entre conteúdo e forma, é fundamental considerar a lei segundo a qual o conteúdo determina a forma, ou seja, o conteúdo é determinante na relação conteúdo/forma, de modo que a forma aparece e muda em resposta às mudanças do conteúdo. Todavia, trata-se de um processo complexo, pois, mesmo estando o conteúdo já modificado, a velha forma pode manter-se por algum tempo, já que esta possui uma relativa autonomia em relação a aquele.

Desse modo, "[...] uma mesma forma, durante algum tempo, pode encarnar em diferentes conteúdos e [...] conteúdos similares podem servir-se de diferentes formas, em seu processo de desenvolvimento." (ROSENTAL; STRAKS, 1960, p. 214). Essa relação é sempre permeada pela transformação, pelo movimento; não há entre essas categorias uma concordância imóvel e absoluta. Assim, o movimento dialético entre conteúdo e forma depende das condições históricas e sociais; não é algo que aconteça de modo natural e sem interferências, como posto por Rosental e Straks (1960, p. 215):

A 'luta' do conteúdo com a forma é uma das forças motrizes do desenvolvimento das coisas, dos fenômenos e de seu trânsito a novos estados qualitativos. No entanto, para não cair em uma concepção superficialmente estreita e unilateral das fontes do desenvolvimento das coisas, deve-se observar que a 'luta' entre o conteúdo e a forma existe sempre dentro de condições concretas.

Assim, a mudança de qualidade envolve a transformação do conteúdo dos objetos, fenômenos ou processos. As mudanças do conteúdo e, por conseguinte, da forma correspondem, então, à passagem de uma qualidade à outra, ou seja, ao surgimento de uma nova qualidade. Esse movimento, que possibilita o surgimento de uma nova qualidade resultante da mudança de conteúdo, tem como motor as contradições. De acordo com Cheptulin (1982, p. 295),

[...] a contradição não é uma coisa fixa, imutável, mas encontra-se em movimento incessante, em mudança permanente, passando das formas inferiores às formas superiores, e vice-versa, enquanto os contrários passam um pelo outro, tornam-se idênticos, e a 
formação material que os possui propriamente entra em um novo estado qualitativo.

O surgimento de um novo estado qualitativo é, desse modo, resultante do movimento gerado pelas contradições, que, conforme Lefebvre (1970) e Cheptulin (1982), se configura na negação do antigo estado qualitativo. A negação, segundo os autores, é um momento necessário do desenvolvimento. Já a superação, entendida como negação da negação, resulta da solução de contradições, em dado contexto e momento histórico.

Ao transformar a antiga qualidade em uma nova qualidade, pela eliminação dos aspectos e das ligações que não correspondem às novas condições, tem-se um processo de desenvolvimento que não segue uma linha diretamente ascendente. $\mathrm{Na}$ verdade, trata-se de um processo que se configura como uma espiral, em que cada volta parece repetir a precedente, mas está sobre uma base mais elevada (CHEPTULIN, 1982; LEFEBVRE, 1970).

Assim posto, olhamos para a forma de organização escolar a partir da compreensão de que ela interfere diretamente na organização, tanto dos processos de formação contínua como nos processos de ensino do professor, e nas aprendizagens tanto dele como de seus alunos. Entendemos que, de modo geral, não há, na organização do tempo escolar, momentos que possam ser destinados a esses processos formativos em que se considerem as necessidades imediatas dos professores sem, contudo, limitar-se a elas.

A partir daí, torna-se fundamental que a apropriação de novos conhecimentos sobre os objetos de ensino e sobre a sua organização, mediada por ações intencionais do formador, propicie aos professores uma compreensão mais ampla de sua atividade de ensino.

Compreendemos, neste sentido, que o movimento formativo tem um papel importante como maneira de organizar a formação contínua no ambiente de trabalho do professor (a escola), formação que é mediada pelo conteúdo representado pelo conhecimento científico dos conteúdos escolares e pelas teorias sobre desenvolvimento e aprendizagem e demais conceitos inerentes ao fazer docente. 
Ao mesmo tempo em que é um universo de formação de professores, o movimento formativo constitui-se como rico espaço também no campo de pesquisa, pois propicia aos pesquisadores condições para que o objeto de suas pesquisas seja captado em seu movimento. Segundo Kopnin (1978), isso implica o exame do objeto em seu próprio movimento, em busca da verdade, através da sua própria demonstração.

Estudar o fenômeno em movimento é, segundo Vigotski (1995, p. 67-68),

[...] exigência fundamental do método dialético. Quando numa investigação se abarca o processo de desenvolvimento de algum fenômeno em todas as suas fases e mudanças, desde que surge até que desapareça, isso implica manifestar sua natureza, conhecer sua essência, já que somente em movimento demonstra o corpo que existe. Sendo assim a investigação histórica da conduta não é algo que complementa ou ajuda o estudo teórico, mas que constitui seu fundamento.

Desse modo, compreendemos que o fenômeno não está dado e, por isso, buscamos, por meio dos procedimentos adotados, “[...] apreender o movimento que leva o profissional professor de uma qualidade a outra. [...] identificar qualidades que possam ser indicativas do fenômeno formação e que nos permitam compreender o modo de formar-se professor" (MOURA, 2000, p. 48), com foco na dialética conteúdo/forma na atividade de ensino.

No tratamento que daremos à pesquisa, objeto de nossas reflexões no presente artigo, buscamos pontuar ações que apontem indícios de mudanças nas concepções sobre atividade e organização do ensino no decorrer da formação contínua, assim como proposições para o enfrentamento das contradições presentes nas formas de organização escolar. Ressaltamos, ainda, que, no processo em que a pesquisa desenvolveu-se, compreendemo-nos como pesquisadores aliados na busca por possíveis soluções aos problemas enfrentados pelos professores na escola, por meio de uma ação mediadora (pesquisadorconhecimento-professores) para o desenvolvimento do pensamento teórico do professor e para uma educação escolar que se fizesse propulsora do desenvolvimento humano.

Os dados empíricos foram apreendidos por gravações em áudio e vídeo de 
todos os encontros de formação, um diário de campo com registro das ações desenvolvidas, das observações realizadas e pelos registros escritos produzidos pelas professoras.

$\mathrm{Na}$ organização e desenvolvimento do movimento formativo, buscamos considerar as necessidades dos professores relacionadas com a sua atividade de ensino, as suas dificuldades para o exercício do ensino de Matemática, tanto as relacionadas aos conceitos específicos como à organização do seu ensino. Pretendíamos que o processo de formação contínua se materializasse por modos de organização pensados a partir da estrutura da atividade, por meio de situações geradoras de motivos que impulsionassem os professores a agir coletivamente através de ações e operações que envolveram estudo, planejamento e avaliação do trabalho desenvolvido em sala de aula.

O trabalho com a resolução de situações-problema, por exemplo, foi o assunto escolhido pelas professoras dos anos iniciais para iniciarmos nossos estudos. Inicialmente, a preocupação foi atender suas necessidades imediatas, pois ainda não conhecíamos bem as profissionais e também ansiávamos por envolvê-las nos estudos propostos. Passamos, então, a realizar encontros quinzenais com grupos de professoras de Educação Infantil, $1^{\circ}$ e $2^{\circ}$ anos; professoras do $3^{\circ}$ ano e professoras de $4^{\circ}$ e $5^{\circ}$ anos. As coordenadoras de cada turma também participavam dos encontros.

A síntese das ações desenvolvidas na maioria dos encontros do movimento formativo de 2013 apontou a prevalência do atendimento das necessidades imediatas das professoras, aquelas diretamente relacionadas com o conteúdo matemático que, naquele momento, estava sendo ensinado aos alunos. A dinâmica que se mantinha no início do movimento formativo revelava um trabalho setorizado, aderente aos moldes da tradicional forma de organização escolar e impossibilitava que as necessidades do coletivo fossem trabalhadas. Não propiciava ações de socialização de experiências, reflexões e conhecimentos entre o universo das professoras participantes de todos os grupos.

Gerar uma necessidade comum ao grupo fez-se necessário, pois, dentro da perspectiva teórica adotada, o trabalho coletivo é elemento chave para que os 
processos de formação docente venham a configurar-se como processos de aprendizagem.

Conforme Rubtsov (2003, p. 134), “[...] a aptidão para a aprendizagem é, na verdade, resultado de uma determinada interiorização, de maneira que a atividade de aprendizagem se apresenta, essencialmente, sob a forma de uma atividade realizada em comum, na qual as tarefas são repartidas entre os alunos, ou entre alunos e professor." E por que não dizer também, repartidas entre os professores, ou entre professores e formador.

Essa necessidade comum emergiu ao final de 2013, quando as coordenadoras da escola solicitaram ajuda para a revisão do plano de ensino anual de Matemática, uma necessidade que já era apontada por algumas professoras em momentos diversos dos encontros de formação, o que demandava a participação de todos os grupos.

Surgiu, então, a possibilidade de desencadear discussões mais amplas acerca do ensino e aprendizagem de Matemática, de forma a envolver os professores em um trabalho conjunto, focando aspectos relacionados com a apropriação do conhecimento matemático e com a organização do ensino.

\section{Corporificação das opções teóricas nos contextos da prática}

Iniciamos 2014 com a tarefa de realizar a revisão coletiva do plano de ensino anual de Matemática. Nossa intenção para aquele ano era realizar encontros coletivos envolvendo os professores de $1^{\circ}$ ao $5^{\circ}$ ano em atividade compartilhada, pois, "para que, subjetivamente, o sujeito sinta novas necessidades ou motivos que o estimulem a agir em um nível superior, é preciso que esteja inserido em um contexto que produza, objetivamente, a necessidade de novas ações." (SFORNI, 2004, p. 104).

Nesta tarefa de revisão coletiva do plano mencionado, foi possível constatar como a forma de organização escolar interfere diretamente na organização dos processos de formação contínua e que, apesar de o discurso oficial propagar a necessidade de oferta de formação contínua aos professores, o 
que se percebe é que não há, na organização do tempo escolar, momentos que possam ser destinados a esses processos.

$\mathrm{Na}$ prática, devido à mudança dos horários, a dificuldade de juntar professores de anos diferentes em um mesmo grupo começa pela falta de horário disponível na forma de organização da escola. Nos horários destinados ao planejamento coletivo, único momento disponibilizado para esses encontros, era possível contar com a presença das professoras somente por ano de atuação.

O enfrentamento de tal contradição foi objeto de discussão coletiva e a necessidade de valorização do movimento formativo foi apontada pelo grupo e considerada pela direção. Como alternativa foi proposta a realização desses encontros em dias destinados no calendário escolar à reunião pedagógica. Porém, não eram muitos os dias e, além disso, a escola tinha também outras ações planejadas para aqueles momentos.

Foram cedidas para tais ações três datas em meses não subsequentes e, para que as ações desenvolvidas não se perdessem pela falta de sistematicidade gerada pela distância temporal entre os encontros coletivos, foi encaminhada a proposta de intercalar o encontro coletivo com encontros em pequenos grupos, o que se concretizou. Assim, a flexibilização de tempos e espaços dentro do que estava oficialmente estruturado tornou-se via através da qual, gradativamente, o grupo passou a buscar a superação das contradições emergentes na forma de organização escolar.

A formação de concepções influenciadas por tarefas a cumprir para atender a necessidades geradas pelas formas de organização escolar aparece também nas falas das professoras de Educação Infantil, primeiro e segundo anos. Suas falas são relevadoras da compreensão de que saber Matemática deve ser preocupação dos professores de terceiro a quinto anos, visto que o foco no primeiro e segundo anos deve ser voltado para a alfabetização. Nessas falas revela-se, ainda, que o atendimento a avaliação externa é tomado como princípio normativo para o movimento curricular.

No encontro de formação realizado em dezembro de 2013, em uma discussão sobre o plano de ensino anual de Matemática com as professoras que 
atuavam no $1^{\circ}$ ano, a preocupação com a alfabetização da língua materna foi apontada pelo grupo.

É o que realmente nos cobram. Ninguém pergunta esse menino sabe [...] (Prof2B); [...] contar até dez [...] (Prof2D); [...] contar até dez, resolver situaçôes-problema? Ele tem um bom raciocínio lógico-matemático? Vão perguntar: ele lê? Ele escreve? É o que o $2^{\circ}$ ano chega e cobra. (Prof2B); [...] Só que eu não sei quem falou também que a gente pode alfabetizar; ensinar a ler e a escrever, ensinando a matemática. (Relembrando discussões realizadas em encontros anteriores). [...] Mas, a gente acaba falhando, errando, mas é uma coisa sem você perceber. (Prof1A); Você pode até olhar, todo mundo que chega pra professora de $1^{o}$ ano, pergunta: Estão todos lendo? Eles fazem produção ou estão fazendo só listinha? (Prof2B).

As falas da Prof2B, respaldadas pelas outras professoras, evidenciam que a cobrança específica se faz em relação à apropriação do sistema de escrita alfabética. Como dito por ela: "É o que realmente nos cobram. Ninguém pergunta: esse menino sabe contar até dez, resolver situações-problema? Ele tem um bom raciocínio lógico-matemático? Vão perguntar: ele lê? Ele escreve? É o que o $2^{\circ}$ ano chega e cobra”.

Em sentido oposto aos os pressupostos de Vigotski (2010, p. 325), tal preocupação contraria o entendimento de que "[...] o desenvolvimento intelectual da criança não é distribuído nem realizado pelo sistema de matérias. Não se verifica que a aritmética desenvolve isolada e independentemente umas funções enquanto a escrita desenvolve outras". Isso mostra que a escola se organiza e cobra justamente o contrário das professoras, o que faz com que elas atendam sem questionar se devem alfabetizar ou ensinar matemática.

Ao dizer que ouviu que é possível alfabetizar e ensinar matemática provavelmente por meio das discussões que permearam os encontros de formação com os grupos de $1^{\circ}$ e $2^{\circ}$ anos -, a Prof1A demonstra que o processo de formação também possibilitou reflexões a esse respeito. Entretanto, alterar a ênfase no trabalho com a língua portuguesa nas turmas de alfabetização em detrimento de aprendizagens de conceitos das demais áreas de conhecimento não é uma tarefa fácil, pois demanda o enfrentamento dessa contradição condicionada pelo teoricamente posto e o que é efetivamente cobrado na prática escolar. 
Se o que se espera é que as crianças aprendam a ler e a escrever e se há, ainda, entre os professores, alguma ideia de que a criança aprende de modo linear e fragmentado, as ações de ensino estarão voltadas para o processo de alfabetização da língua materna, enquanto que o conhecimento matemático será tratado como algo complementar. Contudo, é importante considerar que:

[...] as crianças não precisam, primeiramente, aprender as letras para só depois aprenderem números, formas e outros entes matemáticos, é possível pensarmos em processos de organização do ensino que, ao mesmo tempo em que considerem a especificidade da infância, favoreçam e potencializem diferentes aprendizagens. (MORETTI; SOUZA, 2015, p. 16).

No encontro realizado em março de 2014, essa questão foi retomada pelas professoras. Mesmo se mostrando mais preocupadas com o planejamento de situações voltadas para o ensino e aprendizagem de Matemática, o foco no processo de alfabetização algumas vezes ainda prevaleceu. Mudar tal situação implica, como defendido por Araújo (2007), Moura (2007), Moraes e Vignoto (2013), conceber a Matemática como uma linguagem específica e compreender, ainda, que a sua aprendizagem é também uma necessidade humana.

Ao longo do movimento formativo realizado, buscamos propiciar a discussão dessas ideias com o grupo de professoras, entretanto, avaliando o trabalho desenvolvido, foi possível perceber que, o fato de não ter ocorrido e se fazer necessário um aprofundamento maior dessas questões, não possibilitou que as professoras se apropriassem de novas significações em relação à Matemática como uma linguagem que pudesse refletir-se em mudanças nas formas de organização do ensino.

Entretanto, mesmo que ainda em processo, a reflexão escrita pela Prof1A em dezembro de 2014 ao avaliar o movimento formativo desenvolvido na escola evidencia a possibilidade de mudança, quando aponta que as ações de formação realizadas proporcionaram algumas alterações no modo como as professoras organizavam o ensino de matemática nas turmas de alfabetização.

As contribuições fornecidas durante a formação continuada sobre $o$ ensino e a aprendizagem de conhecimentos matemáticos nos proporcionaram uma reflexão sobre o nosso trabalho em relação à matemática, visto que, como professoras de alfabetização, 
acabamos, mesmo sem intenção, focando mais na língua portuguesa. [...] tivemos oportunidade de discutir e refletir que a matemática pode ser trabalhada de maneira prazerosa, com jogos e brincadeiras, que envolvem também a língua portuguesa, [...]. Dessa forma, [...] a formação foi de grande valia e fez com que meu olhar diante da matemática ficasse mais claro [...]. (Prof1A).

A necessidade de a Matemática ser concebida como uma linguagem implica um trabalho que vai muito além da simples preocupação demonstrada pelas professoras em articular os conteúdos de Matemática com os de língua portuguesa, pois a forma de ensinar também está inter-relacionada com o sentido que o ensino de conhecimentos matemáticos tem para as professoras. Entretanto, entendemos que as discussões desenvolvidas pelo grupo foram desencadeadoras de novas aprendizagens.

Como aponta Catini (2013), quando a forma escolar sobrepõe-se ao conteúdo da educação escolar, o que faz com que a forma prevaleça sobre a formação, a importância da apropriação de conhecimentos científicos fica minimizada e a ênfase no desenvolvimento de competências e habilidades marca uma realidade que dificulta o desenvolvimento do pensamento teórico dos próprios professores, tanto na formação inicial como na formação contínua. Desse modo, as mudanças no conteúdo e forma da atividade do professor, que se encontra aprisionado pelas condições descritas, ficam atreladas às mudanças no conteúdo e forma da própria educação escolar.

Porém, para que haja mudanças na forma da atividade de ensino é preciso possibilitar aos professores a apropriação de novas significações acerca do próprio objeto de ensino (no caso de nossa investigação, conhecimentos matemáticos), ou seja, o conteúdo da atividade de ensino precisa ser modificado, pois a mudança da forma está sujeita à mudança do conteúdo (CHEPTULIN,1982; FISCHER,1976; ROSENTAL; STRAKS,1960).

Outra questão a ser destacada é a afirmação feita pela Prof2A, em um dos encontros realizados, de que, apesar de saber que a organização do ensino de outro modo favoreceria a aprendizagem das crianças, é difícil mudar em virtude das cobranças e do calendário escolar (período de avaliação, encerramento do 
bimestre). A situação relatada por essa professora reforça a influência da forma escolar no trabalho do professor, que, mesmo identificando a necessidade de alterar o seu modo de organização do ensino, não consegue fazê-lo sozinho.

Inferimos, ainda, que as dificuldades em mudar a forma da atividade de ensino do professor para além da resistência da própria forma escolar pode, também, estar relacionada com a falta de convicção e/ou de conhecimento de que as crianças realmente podem aprender a partir de outro modo de organização que privilegie a exploração dos nexos conceituais ao invés da quantidade de conteúdo.

Algumas ações desenvolvidas ao longo do movimento formativo, como a proposta de discussão e revisão coletiva do plano de ensino anual de Matemática, contribuíram para que o grupo de professoras pudesse refletir sobre a atual forma de organização escolar e as suas contradições. A proposta de analisar em conjunto o plano de ensino anual de Matemática constituiu-se como um pontapé a partir do qual desejávamos que fossem geradas novas necessidades de formação.

O trabalho coletivo de revisão do plano de ensino anual de Matemática e a discussão acerca da distribuição dos conteúdos ao longo de cada ano promoveram a reflexão das professoras sobre o modo como organizam o ensino de Matemática e possibilitaram a apropriação de conhecimentos teóricos sobre a própria atividade de ensino.

No encontro realizado com o grupo que atuava no $4^{\circ}$ ano, a discussão sobre revisão da ementa contribuiu para que se pudesse repensar sobre o modo como organizavam o ensino de Matemática e também sobre mudanças que poderiam ser realizadas, uma vez que perceberam que cada conteúdo matemático não precisava ser trabalhado isoladamente, mas havia a possibilidade de estabelecerem-se relações entre eles e, assim, ensiná-los de modo global.

A proposta de explorar os conteúdos matemáticos de modo articulado pode ser interpretada como um indício de mudança na forma de organizar o ensino, já que as professoras no início do movimento formativo não discutiam essas possibilidades. Podemos inferir que as ações dessas professoras ganharam nova qualidade em virtude de mudanças no conteúdo da atividade de ensino. 
Assim, para a contradição posta pela relação que estabeleciam entre a quantidade de conteúdos e o tempo que tinham para a sua abordagem, surgiu como via de superação a possibilidade de mudança nas formas de organização do ensino quando focadas nos nexos dos conceitos a serem trabalhados.

Outra contradição explicitada nas relações com as professoras foi a da avaliação externa tomada como princípio normativo para o movimento curricular, contradizendo o papel da avaliação de referenciar-se no currículo para o estabelecimento das características que deve assumir. Ao longo do movimento formativo, as professoras chamaram atenção para o peso que os resultados das avaliações em larga escala exercem na seleção dos conteúdos e também no modo como organizam o ensino.

Ao demonstrarem as suas preocupações com os resultados obtidos pela escola em Matemática ${ }^{6}$, as professoras indicaram que melhorar esses índices pode ter sido um dos motivos que levou a escola, representada pelas diretoras e coordenadoras, a aceitar participar de um processo de formação contínua sobre Matemática. No encontro realizado em dezembro de 2013, durante discussão sobre o plano de ensino anual de Matemática, as professoras do $4^{\circ}$ e $5^{\circ}$ ano fizeram referência ao fato dos resultados de Matemática da escola nas avaliações em larga escala não estarem a contento.

[...] eu vou falar uma coisa pra você, o negócio está feio. (risos) A gente melhorou um pouco, mas o negócio ainda está feio. (Prof5A). Os resultados ainda mostram que a matemática está baixa. (Prof4B)

Falas semelhantes, referindo-se aos baixos resultados obtidos pela escola em Matemática, ocorreram em outros momentos ao longo do movimento formativo, principalmente pelas professoras do $4^{\circ}$ e $5^{\circ}$ anos. Podemos, então, conjecturar que talvez a participação de algumas professoras no processo de

\footnotetext{
${ }^{6}$ As avaliações em larga escala realizadas, no período, pelas turmas de $1^{\circ}$ ao $5^{\circ}$ ano dos anos iniciais das escolas públicas de Campo Grande/MS foram: Provinha Brasil; Avaliação Nacional da Alfabetização - ANA; Avaliação externa (realizada pelo próprio município, aplicada aos alunos do $4^{\circ}$ ano por uma equipe externa a cada dois anos, intercalando a aplicação da Prova Brasil); Prova Brasil.
} 
formação contínua possa ter tido como motivo melhorar os resultados de sua turma nas avaliações em larga escala.

Se assim foi, inicialmente, elas não estariam em atividade, estariam realizando apenas uma ação, pois somente os motivos eficazes, que coincidem diretamente com o objeto, no caso o conhecimento matemático, garantem as condições da atividade. Contudo, como ilustra a fala da Prof5A a seguir, coletada durante outro encontro de formação realizado em março em 2014, denota que os motivos compreensíveis podem ter se tornado motivos eficazes.

Não adianta a gente ser inocente e falar que não estamos preocupados com a avaliação externa, com a Prova Brasil, porque é isso que dita o que é cobrado. Mas hoje aqui e no ano passado que você veio e que a gente está estudando, nós estamos estudando por uma preocupação da escola em relação à matemática, em relação à aprendizagem. Mas não porque alguém lá da SEMED veio pra fazer análise daquilo que a gente não acertou, não. Então, isso é a nossa escola. E as outras escolas que não estão nem aí, porque não tem esse tempo, porque não tem mesmo esse tempo de estudar. [...] Nós somos privilegiadas porque temos esse tempo de estudo. (Prof5A)

É importante destacarmos, na fala da Prof5A, a afirmação de que as avaliações em larga em escala é que ditam o que será cobrado, ou seja, determinam o que deve ser ensinado. Isso também pode ser identificado na fala da Prof2 durante o encontro de formação realizado em dezembro de 2013, ao justificar algumas modificações realizadas na ementa do $2^{\circ}$ ano quando a analisamos com o grupo.

[...] a gente sempre teve o problema de matemática ser muito fraca e, então, a gente se reuniu no ano passado [...]. A gente quis puxar essa matemática. A gente falou: 'Vamos desafiar, vamos ver se a gente consegue.' Até porque tinha prova de avaliação externa e eles não tinham noção do que era o conteúdo, porque não tinha sido trabalhado. A gente estava com um limite. Então, a gente tentou ultrapassar esse limite, mesmo que talvez não da forma mais adequada, mas a gente tentou ultrapassar porque a gente acreditava que as crianças talvez viessem mais bem preparadas, porque às vezes um ano é melhor, o outro nem tanto. Enfim a gente tentou, mas teve coisa que não conseguiu alcançar nessa ementa. (Prof2) 
Ao assumir que foram incluídos alguns conteúdos na ementa porque a Matemática estava "fraca", a Prof2 tem como parâmetro as avaliações em larga escala. Há, assim, uma determinação do currículo de ensino em função das matrizes de referência, ou seja, ao invés de pensar o ensino a partir dos nexos conceituais dos conteúdos, buscando a apropriação de conceitos científicos, o que se considera são as competências e habilidades que serão cobradas nas avaliações em larga escala. Essa situação reforça o peso que a forma escolar exerce na atividade do professor.

Conforme Esteban e Lacerda (2012, p. 458), essa perspectiva das avaliações em larga escala leva a aprendizagem a ser reduzida “[...] a armazenamento e reprodução das informações estabelecidas como relevantes e a avaliação se traduz em atividades simplificadoras que permitem a aferição do desempenho a partir de padrões predeterminados.” Esse tipo de prática, além de interferir nos conteúdos a serem ensinados, também interfere no modo como o ensino é organizado.

O projeto de avaliação do sistema educacional brasileiro, apesar do discurso posto - que é o de contribuir para o planejamento de políticas públicas a partir dos dados obtidos - vem interferindo diretamente na sala de aula, pois a avaliação das aprendizagens no cotidiano escolar a cada dia é mais condicionada pelas avaliações em larga escala. Para Esteban e Lacerda (2012, p. 262, grifo do autor), essa prática “[...] induz a escola ao treinamento, em detrimento da relação aprendizagem-ensino, para alcançar o padrão validado, e se incrementa a preocupação docente com metas, índices e descritores, vinculados ao resultado".

No entanto, mesmo diante dessa realidade e tentando superar tal contradição, ainda foi possível seguirmos na contramão, usando os resultados obtidos com as avaliações externas para repensar os processos de ensino e aprendizagem para além do treino e da repetição. Em dezembro de 2014, no último encontro de formação realizado com o grupo do $5^{\circ}$ ano, ao comentar sobre a prova da avaliação externa aplicada aos alunos do $4^{\circ}$ ano pela SEMED, a Coord3 manifestou interesse em dar continuidade aos estudos em relação à Matemática. 
[...] ainda me preocupa a avaliação externa. Eu gostaria de organizar para o ano que vem, da mesma forma que fizemos esse trabalho bacana em relação ao sistema de numeração decimal, eu gostaria de ter esses momentos de discussão dentro da geometria, as figuras... Ter esse momento de discussão pra trabalhar a questão de tempo e da hora... Gente, caíram duas questões de tempo e, às vezes, não que a gente não trabalhe, trabalha, mas não paramos para discutir isso. $(\mathrm{Coord} 3)$

Talvez o motivo que a leve agir ainda seja um motivo compreensível, contudo, como vivenciado ao longo do movimento formativo, é possível que os motivos compreensíveis transformem-se em motivos eficazes. Assim sendo, a preocupação com os resultados das avaliações externas também pode constituirse como uma situação desencadeadora para, a partir dos pressupostos da teoria histórico-cultural, repensar-se o ensino, os seus modos de organização e refletir sobre os significados da avaliação no cotidiano escolar.

Destarte, tomar a revisão do plano de ensino anual de Matemática como um problema a ser resolvido coletivamente possibilitou ao grupo refletir sobre alguns de seus conhecimentos matemáticos e sobre a própria organização do ensino. As questões relacionadas com as avaliações em larga escala e, também, o ensino de Matemática no ciclo de alfabetização fizeram-se presentes nos encontros para a revisão.

Entretanto, cabe destacar que o modo de organizar o ensino e a preocupação frequente com o cumprimento do plano de ensino anual demonstrada pelas professoras ao longo do movimento formativo - é resultante da organização da forma escolar atual, produzida a partir de relações produtivistas, nos moldes empresariais.

Nas palavras de Catini (2013, p. 98-99, grifos do autor), “[...] na vida escolar capitalista cada hora é hora de muito trabalho. [...] Esse tempo de vida corresponde a um incessante fazer, quase sempre um fazer automático e alienado, no interior de um tempo vazio e desprovido de conteúdo". A partir dessa lógica, o trabalho do professor fica, portanto, reduzido ao cumprimento de uma listagem de conteúdos, que é constituída como se fosse uma linha de montagem, que determina o que o professor de cada ano escolar deve cumprir. 
Reafirmarmos, nesse contexto, a complexidade do conteúdo da atividade de ensino, o que exige o desenvolvimento do pensamento teórico do professor e a sua reflexão para além do modo de organização da escola atual. Cabe ressaltarmos, como explicitado por Kopnin (1978, p.24), que "a passagem do nível empírico ao teórico não é uma simples transferência de conhecimento da linguagem cotidiana para a científica, mas uma mudança de conteúdo e forma do conhecimento".

Logo, possibilitar o desenvolvimento do pensamento teórico do professor num processo de formação contínua não é algo simples nem tarefa fácil. A mudança de conteúdo da atividade de ensino e, por conseguinte, da sua forma, depende, portanto, de ações intencionais, que possibilitem ao professor dominar instrumentos teóricos por meio do estudo dos fundamentos teóricos da educação, das políticas educacionais e das teorias de ensino, além de conhecer os aspectos lógico-históricos de seu objeto de ensino.

Assim, se pretendemos operar mudanças no quadro atual da escola brasileira, necessário faz-se rever conteúdo e forma dos modos de organização nos processos de formação de professores, objetivando organizar,

[...] ambientes formativos que a eles [professores] possibilitem superar o pensamento empírico pelo teórico, que na sua continuidade, interação e complexização promovam a mudança dos sentidos que atribuem aos objetos que sustentam sua ação pedagógica. [...] pois é nos processos de interação que estes podem se modificar, podem tomar lugar das antigas concepções, novas construções e conhecimentos, movimento que leva o professor à superação de uma qualidade antiga por uma nova e outra qualidade. (SOUZA, 2013, p. 43).

Desse modo, a superação de uma qualidade antiga por uma nova e outra qualidade nas ações dos professores envolverá tomar o conhecimento científico como conteúdo da atividade de formação do professor, objetivando desenvolver o seu pensamento teórico, de modo que as ações realizadas propiciem mudanças na forma e no conteúdo da atividade de ensino dos professores. Como posto por Fischer (1976, p. 146), "a forma, aquilo que persiste em um estado de equilíbrio relativamente estável, está sempre sujeita a ser destruída pelo movimento e pela mudança do conteúdo". 
A valorização e a efetivação do trabalho coletivo na escola, juntamente com o desenvolvimento do pensamento teórico do professor, tornam-se, portanto, elementos indispensáveis no processo de mudança. As situações que incentivaram o trabalho coletivo propiciaram às professoras, através do motivo comum de elaborar, desenvolver e avaliar as atividades de ensino durante o movimento formativo realizado, a oportunidade de reconhecer, que "pensar juntas" (Prof5B) contribuiu para melhorar a qualidade das ações.

O registro produzido pelas Prof2B, Prof2C e Prof2D ao avaliarem o movimento formativo desenvolvido na escola em dezembro de 2014 também destaca a importância do trabalho coletivo e manifesta o desejo de continuarem os estudos.

Consideramos de grande valia o estudo realizado ao longo de 2014, principalmente a contribuição dos textos complementares sugeridos pela pesquisadora. Sugerimos que, para o ano que vem, $o$ estudo tenha uma organização diferente, utilizando mensalmente o horário de um HTPA secundário (2h) e que dure de março a novembro de 2015. Seria interessante montarmos um plano de trabalho com cronograma fixo e leituras, para que possamos nos organizar melhor e assim podermos desenvolver com qualidade tanto o estudo quanto nosso trabalho na escola. Além das contribuições ao nosso enriquecimento teórico, percebemos que é produtivo discutir com os pares as questões que mais nos afligem na prática e buscar soluçôes para elas. Por fim, agradecemos a disponibilidade da pesquisadora e sua paciência com nossas dúvidas e anseios. (Prof2B, Prof2C e Prof2D)

O fato da proposição de um modo de sistematizar a continuidade da formação contínua para o próximo ano partir das professoras revela o seu reconhecimento como gestoras de seus processos formativos com autonomia para intervir na destinação dos tempos e espaços constituintes da forma escolar.

Ao declararem "[...] percebemos que é produtivo discutir com os pares as questões que mais nos afligem na prática e buscar soluções para elas", as professoras evidenciam que o trabalho coletivo trouxe contribuições para a sua prática, uma vez que a busca de soluções para os seus problemas pôde partir de ações coletivas, possibilitando, assim, ao organizar o trabalho coletivamente, que a qualidade das próprias relações de trabalho dentro da escola seja alterada (ARAÚJO, 2009). 
Essas mudanças foram desencadeadas em virtude das alterações ocorridas no conteúdo da atividade de ensino, geradas, principalmente, a partir da reflexão realizada acerca da escolha dos instrumentos de ensino e do próprio conteúdo a ser ensinado, as quais possibilitaram às professoras - por meio das mediações realizadas - a apropriação de novas significações.

\section{Considerações}

O foco das questões apresentadas e discutidas no presente artigo foi a formação contínua de professores marcada pelos avanços e retrocessos influenciados pelas políticas educacionais e a busca de referenciais que possam estruturar movimentos de formação voltados ao desenvolvimento das máximas potencialidades humanas.

Aqui, foram apontados como contradições a serem superadas pelas propostas de formação contínua o esgotamento dos modelos até então praticados para chegarmos a esse intento e os empecilhos encontrados na atual forma escolar, fundamentada em concepções que mais se aproximam das necessidades produtivistas do mercado empresarial do que as da própria formação e desenvolvimento humano, que seria o papel da educação escolar.

Isso implica processos formativos contínuos na e com a escola e o exercício constante de superação da forma escolar atual que, tal como se apresenta, não estabelece espaço para o trabalho coletivo, pois o crescente grau de divisão do trabalho na escola e a fragmentação das tarefas realizadas pelos professores, além de dificultarem o desenvolvimento de ações coletivas, valorizam o trabalho individual e incentivam a competitividade tanto entre os alunos como entre os próprios professores.

Destacamos, ainda, que a superação dessa situação exige, para além do modo de organização da escola atual, a compreensão sobre a complexidade do conteúdo da atividade de ensino, o que requer que os professores apropriem-se de novas significações sobre o próprio objeto de ensino, os processos de 
desenvolvimento infantil, as práticas pedagógicas e outros aspectos que medeiam a sua atuação no contexto escolar.

A alteração do conteúdo da atividade de ensino depende, por conseguinte, da própria atividade desenvolvida pelo professor tanto nos processos de formação como em sua atuação na escola. É apenas no processo de apropriação de conhecimentos teóricos sobre o objeto de ensino, como sujeito da aprendizagem e nas relações estabelecidas entre os processos de ensinar e aprender, que o professor poderá desenvolver o seu pensamento teórico e, então, alterar o conteúdo da atividade de ensino, possibilitando mudanças na sua forma.

Ao tomar como objeto da formação contínua a atividade de ensino, levamos o professor a refletir sobre as suas ações de formação e ensino para que, por meio de apropriação de novos conhecimentos, possa modificá-las. Outro aspecto destacado no processo de realização de atividades de ensino ao longo do processo de investigação foi a sua contribuição para o desenvolvimento do próprio trabalho coletivo na escola.

Ao mesmo tempo em que o trabalho coletivo, no decorrer do movimento formativo, foi apresentado como uma necessidade do grupo de professoras e coordenadoras, ele também se configurou como um desafio, pois trabalhar coletivamente não significa apenas estar junto. Ao contrário, é preciso que o grupo constitua-se coletivamente e, para tanto, desenvolva uma atividade conjunta de modo que as suas ações estejam vinculadas a um objeto do coletivo.

Tal alcance não se dá facilmente nem tampouco espontaneamente, mas depende de metas que precisam estar articuladas às expectativas da comunidade escolar, expressas no Projeto Político Pedagógico da escola e, também, na atividade de ensino do professor, que orientarão as ações que tornarão possível concretizar essas metas, que satisfaçam tanto o indivíduo como o próprio grupo.

Assim posto, propor-se a desenvolver ações coletivas de trabalho na escola implica caminhar na contramão da realidade posta pela forma escolar, o que buscamos fazer ao longo de todo movimento formativo, em defesa do papel humanizador da educação escolar. 
Além disso, o ato de planejar, desenvolver e avaliar atividades de ensino em parceria com outros professores, como observamos durante o movimento formativo, pode suscitar a criação de novas necessidades e a apropriação de novos conhecimentos, os quais podem levar os professores a produzir outros sentidos às ações desenvolvidas.

Defendemos, desse modo, que as mudanças na forma de organização do ensino, como já posto na dialética conteúdo/forma, dependem de alterações no conteúdo da atividade de ensino, uma vez que o conteúdo opera como princípio orientador da forma.

Porém, é fundamental compreender que essa é uma relação complexa, pois, como explicado nos fundamentos dos autores em que nos apoiamos para fundamentação teórica do estudo e observado no movimento formativo desenvolvido na pesquisa apresentada, o conteúdo provoca mudanças em sua forma, mas a forma também influencia no desenvolvimento do conteúdo.

Além disso, o processo de mudança da forma em consequência do conteúdo demanda tempo, pois, apesar do conteúdo estar em constante movimento e transformação, a forma oferece-lhe resistência. Apenas quando há um agudo conflito entre o novo conteúdo e a velha forma é que uma nova forma origina-se. Isso demanda intencionalidade, paciência, persistência e continuidade dos processos formativos e, ainda, necessariamente que se considere, na análise das relações entre conteúdo e forma na atividade do professor, as condições concretas de sua realidade, pois, como anteriormente apontado, o movimento dialético entre conteúdo e forma não acontece de modo natural e sem interferências, mas está condicionado às condições históricas e sociais.

Em síntese, apontamos que ações de formação efetivamente transformadoras da educação escolar dependem de processos de formação que realmente configurem-se como atividade para o professor e também como via de superação das contradições geradas pelas atuais condições concretas de trabalho, aspecto relacionado com modificações na atual forma de organização escolar, ou seja, é preciso que as contradições que envolvem a forma escolar atual e a atividade do professor sejam superadas. 


\section{Referências}

ARAÚJO, E. S. O projeto de matemática como (des)encadeador da formação docente. In: MIGUEIS, M.R.; AZEVEDO, M. G. (Orgs.). Educação Matemática na infância: abordagens e desafios. Serzedo: Gailivro, 2007, p. 25-38.

ARAÚJO, E. S. Mediação e aprendizagem docente. In: Encontro Nacional de Psicologia Escolar e Educacional ABRAPEE - Construindo a Prática Profissional na Educação para Todos, IX, 2009, São Paulo. Anais. São Paulo: Universidade Presbiteriana Mackenzie, 2009, p. 1-15. Disponível em:

<http://www.abrapee.psc.br/documentos/cd_ix_conpe/IXCONPE_arquivos/26.pdf $>$ . Acesso em: 10 abr. 2016.

CANÁRIO, R.. A escola e as “dificuldades de aprendizagem”. Psic. da Ed., São Paulo, 21, $2^{\circ}$ sem. de 2005, pp. 33-51.

CATINI, C. R. A escola como forma social: Um estudo do modo de educar capitalista. Tese (Doutorado em Educação). USP, São Paulo, 2013.

CHEPTULIN, A. A dialética materialista: categorias e leis da dialética. Tradução de Leda Rita Cintra Ferraz. São Paulo: Editora Alfa-Omega, 1982.

DAVÍDOV, V. La enseñanza escolar y el desarrollo psíquico. Moscú: Editorial Progresso, 1988.

DAVYDOV, V. Tipos de generalización en la enseñanza. Habana: Editorial Pueblo y Educación, 1982.

ESTEBAN, M, T; LACERDA, M. P. de. Em histórias cotidianas, convites ao encontro entre avaliação e aprendizagem-ensino. In: José Carlos Libâneo; Nilda Alves. (Org.). Temas de Pedagogia: diálogos entre didática e currículo. São Paulo: Cortez, 2012, p. 452-465.

ESTEVES, A. K. Números Decimais na Escola Fundamental: Interações entre os conhecimentos de um grupo de professores e a relação com sua prática pedagógica. Dissertação (Mestrado em Educação Matemática). UFMS, Campo Grande/MS, 2009.

FISCHER, E. A necessidade da arte. 5. ed. Rio de Janeiro: Zahar Editores, 1976.

GATTI, B. A.; BARRETO, E. S. (Org.). Professores do Brasil:impasses e desafios. Brasília: UNESCO, 2009 
KOPNIN, P. V. A dialética como lógica e teoria do conhecimento. Rio de Janeiro: Civilização Brasileira, 1978.

LEFEBVRE, H. Lógica formal, lógica dialéctica. Trad. Maria Esther Benithez Eiroa. Espanha: Siglo Veintiuno de España Editores SA, 1970.

LEONTIEV, A. N. Actividad, conciencia, personalidad. Habana: Editorial Pueblo y Educación, 1983.

LEONTIEV, A. N. O desenvolvimento do psiquismo. Tradução de Rubens Eduardo Frias. 2. ed. São Paulo: Centauro, 2004.

LEONTIEV, A. N. Uma contribuição à teoria do desenvolvimento da psique infantil. In: VIGOTSKII, L. S.; LURIA, A. R.; LEONTIEV, A. N. (Org.)

Linguagem, desenvolvimento e aprendizagem. 11. ed. São Paulo: Ícone, 2010, p. 59-84.

MARTINS, L. M. O legado do século XX para a formação de professores. In: MARTINS, L. M; DUARTE, N. (Org.). Formação de professores: limites contemporâneos e alternativas necessárias. São Paulo: Editora UNESP; São Paulo: Cultura Acadêmica, 2010, p. 13-31.

MORAES, S. P. G.; VIGNOTO, J. O ensino de Matemática nos primeiros anos de escolarização: uma análise sobre os cadernos dos escolares. Rev. Teoria e Prática da educação, v. 16, n. 3, p. 115-124, set./dez., 2013.

MORETTI, V. D.; SOUZA, N.M.M.; Educação Matemática nos anos iniciais do ensino fundamental: princípios e práticas pedagógicas. São Paulo: Cortez, 2015. (Coleção biblioteca básica de alfabetização e letramento)

MOURA, M. O. de. A dimensão da alfabetização na educação matemática infantil. In: KISHIMOTO, T. M.; OLIVEIRA-FORMOSINHO, J. (org.). Em busca da pedagogia da infância: pertencer e participar. Porto Alegre: Penso, 2013. p. 110-135.

MOURA, M. O. de. Matemática na Infância. In: MIGUEIS, M.R.; AZEVEDO, M. G. (Orgs.). Educação Matemática na infância: abordagens e desafios. Serzedo: Gailivro, 2007, p. 39-63.

MOURA, M. O. de. O educador matemático na coletividade de formação: uma experiência com a escola pública. (Tese Livre Docência em Educação). USP, São Paulo, 2000.

MOURA, M. O. de. (Coord.). Controle da Variação de Quantidades: atividades de ensino. São Paulo, Universidade de São Paulo, 1996. 
MOURA, M. O. de; MORETTI, V. D. Atividade Orientadora de Ensino: unidade entre ensino e aprendizagem. Revista Diálogo Educacional, 2010.

NACARATO, A. M.; MEGALI, B. L. S.; PASSOS, C. L. B. A matemática nos anos iniciais do Ensino Fundamental: tecendo fios do ensinar e do aprender. Belo Horizonte/MG: Autêntica, 2009.

ROSENTAL, M. M.; STRAKS, G. M. Categorias del materialismo dialectico. Tradução de Adolfo Sanchez Vasquez e Wenceslao Roces. México: Editorial Grijalbo, 1960.

RUBTSOV, V. A atividade de aprendizado e os problemas referentes à formação do pensamento teórico nos escolares. In: GARNIER, C.; BERNARZ, N.; ULANOVSKAYA, I. (Org.). Após Vigotski e Piaget: perspectiva social e construtivista. Escola russa e ocidental. Porto Alegre: Artes Médicas.

Recebimento: 16.05 .18

Aprovação: 28.05.18 